\title{
Domiciliary nebulisers in asthma: a district survey
}

\author{
CLARE M LAROCHE, ANABEL V K HARRIES, RICHARD C F NEWTON, MARK G BRITTON
}

\begin{abstract}
Fifty three patients who were found to be using a home nebuliser for asthma completed a questionnaire. The results showed some confusion about the criteria for recommending whether a patient should buy a nebuliser and for its correct use. Twelve patients had not received any instruction on the use of their nebuliser, and only 11 of those old enough used a peak flow meter in conjunction with it. Eight patients aged 7-15 were using inhaled sympathomimetic aerosols only at the time of buying a nebuliser as compared with most of the older patients, who were using regular oral steroids. Forty nine patients assessed their asthma as moderate to severe, but eight of these were not attending a hospital clinic. Several patients were using $20 \mathrm{mg}$ salbutamol or more every day, and on occasion doses of up to $50 \mathrm{mg}$ a day were reported.

It is recommended that patients should be assessed before they buy a nebuliser and advice given on correct use by a district nebuliser service, organised either by respiratory function technicians or in physiotherapy departments for adults together with a paediatric health visitor for children.
\end{abstract}

\section{Introduction}

In New Zealand the incidence of deaths from asthma has increased disturbingly, ${ }^{1}$ and a lesser trend has been reported in Great Britain. ${ }^{2}$ In 1965 overreliance on the newly introduced sympathomimetic aerosols was postulated as the most likely explanation for a previous peak. ${ }^{3}$ The recent rise in mortality

St Peter's Hospital, Chertsey, Surrey KT16 OPZ

CLARE M LAROCHE, BSC, MB, senior house officer ANABEL V K HARRIES, MB, BS, research fellow

RICHARD C F NEWTON, MB, MRCP, consultant paediatrician

MARK G BRITTON, MD, MRCP, consultant physician

Correspondence and requests for reprints to: Dr Mark Britton. in New Zealand has also been linked with a noticeable increase in the prescribing of aerosols ${ }^{4}$ and overreliance on home nebulisers. ${ }^{5}$

Two patients presented to our hospital, causing us concern about their use of home nebulisers. One was an 18 year old girl with moderately severe asthma, who was admitted with cyanosis and respiratory failure. She had required several courses of oral steroids in the past, and it was assumed that she was taking her prescribed salbutamol and beclomethasone inhalers. This was not the case, however, as she had stopped them and was relying on irregular use of a nebuliser to relieve her symptoms. On the night of admission she had used her home nebuliser to administer salbutamol on three occasions but had taken no further action despite worsening symptoms. She was found by her sister in the early hours of the morning in extreme respiratory distress and semiconscious, but she responded to conventional management on arrival in the casualty department. The other patient was an 8 year old boy who had been prescribed two salbutamol nebules $(5 \mathrm{mg}$ ) regularly three times daily by his general practitioner and whose parents were giving him two additional nebules ( $5 \mathrm{mg}$ ) before athletics training. When interviewed his mother reported that he had been well enough to stop all other conventional treatment, including his steroid inhaler, and subsequently she had been reluctant to decrease the dose of salbutamol that he was receiving. Not surprisingly, on examination he had considerable tachycardia.

These two cases, together with other disquieting reports such as the unprescribed use of a nebuliser by family and friends, prompted us to assess various aspects of the use of home nebulisers in our district.

\section{Method}

A questionnaire that attempted to investigate the areas of concern was devised. The questions were about severity of asthma, type of medical supervision and treatment at the time the nebuliser was bought, reasons for buying the nebuliser, instructions on use, including the use of a peak flow meter, frequency of use and dose of bronchodilator used, side effects, prevalence of failure of the nebuliser to relieve symptoms and subsequent action, prevalence of sharing the nebuliser, and whether there had been any subjective improvement in asthma after buying the nebuliser. All general practitioners in the district (population 220 000) were asked to supply the names 
of patients in their practice who had a home nebuliser for treating asthma. Hospital consultants (chest and paediatric) and companies who supply nebulisers were asked to do the same. The companies would not divulge names but suggested that in future they would ask clients if they objected to their names being given to the hospital.

Patients attending the paediatric clinic were visited by the health visitor, who interviewed a parent. The remaining questionnaires were sent to the relevant general practitioners, who distributed them to their patients.

\section{Results}

Fifty six patients were identified, of whom 53 completed the questionnaire. Twenty seven patients were aged under 7,12 were aged 7-15, eight were aged 16-54, and six were aged over 54 . Thirty eight patients had had home nebulisers for over a year, and 24 children had nebulisers on extended loan from the paediatric clinic. Thirty patients used a nebuliser regularly at least once a day, although 15 of the younger children were using it mainly for prophylactic sodium cromoglycate as they were unable to use conventional metered dose inhalers. Only five children, however, were using the nebuliser for sodium cromoglycate alone. Five patients used their nebuliser more than once a week but not every day, and 18 used it less than once a week.

Severity of asthma when nebuliser was bought-Forty nine patients assessed their asthma as either moderate or severe when they bought the nebuliser, although eight of these were not attending a hospital outpatient clinic. Four patients thought that their asthma was mild, of whom three were attending a hospital clinic. Twenty nine patients experienced symptoms over half of the time, while seven experienced symptoms only a quarter of the time or less.

Previous treatment -In the youngest age group (under 7) 22 children were using oral bronchodilator syrups at the time the nebuliser was bought, although three were not using any regular treatment. Similarly, eight of those aged 7-15 were using sympathomimetic agents alone and only four had used steroid aerosols. Most of the older patients (aged 16 or over) were using continuous or frequent doses of oral steroids as well as inhaled steroids.

Advice given to patients - Thirty two patients had been advised to use a home nebuliser by the hospital and 16 by their general practitioner. The remaining five said that they had been advised by a friend or relative, or by no one. The two main groups did not differ appreciably in their previous treatment or severity of asthma. Reasons given for purchase were: conventional treatment not controlling symptoms (12 patients); child too young for conventional treatment (23); to reduce the number of hospital admissions (13); and to reduce conventional treatment (four). The most popular nebuliser was the PORTA-NEB 40 (Medic-Aid, Chichester), which was used by 24 patients, although 11 different types were represented in all. Twelve patients had not received any instruction on the use of their nebuliser, although all patients felt confident that they were using their nebuliser correctly. Only 11 of the 26 patients aged over 6 , however, and therefore technically able, were using a peak flow meter in conjunction with their nebuliser.

The dose of bronchodilator varied widely (table I). Thirty three patients used Ventolin nebules $(2.5 \mathrm{mg}$ salbutamol/nebule); the remainder used Ventolin solution $(5 \mathrm{mg} / \mathrm{ml})$ diluted in physiological saline. Of the 11 children aged under 7 who used their nebuliser regularly every day, eight used at least $10 \mathrm{mg}$ salbutamol a day. Four children (aged 2-4) used $15 \mathrm{mg}$ salbutamol regularly every day in divided doses. One child aged 8 and one patient in the group aged $16-55$ used $30 \mathrm{mg}$ salbutamol. Of those aged over 55 , three patients regularly used at least $20 \mathrm{mg}$ salbutamol a day. The maximum daily dose of salbutamol taken during acute exacerbations also varied widely. Table II shows that several patients took $30-50 \mathrm{mg}$ salbutamol a day during exacerbations, and some of these were children.

Outcome-Forty six patients thought that their asthma had improved after the purchase of a nebuliser. Most of the children aged under 7 had reduced their use of salbutamol syrup. Five patients had reduced the use of conventional inhalers, and 10 had less need for oral steroids. Of the 27 patients who had been admitted to hospital on more than two occasions before buying a nebuliser, 24 thought that the nebuliser had reduced the frequency of admissions. Twenty nine, however, said that the nebuliser occasionally failed to relieve their symptoms, and nine reported that they occasionally felt worse.

Side effects-In all, 23 patients experienced side effects from their nebuliser. The most common of these was tremor (12 patients). Palpitations were experienced by nine patients. Other side effects mentioned were restlessness, hyperactivity, twitchiness, lightheadedness, "high," drowsiness, vomiting, and tearfulness.

Action if symptoms were not relieved-Patients who said that their symptoms were occasionally unrelieved by the nebuliser were asked to outline their subsequent action. Thirty eight said that they would call in their general practitioner for help or go directly to hospital, although five said that they would take further doses of nebulised salbutamol before seeking expert help.

Sharing of the nebuliser-Fourteen patients shared their nebuliser with a relative; most of these relatives, however, had been advised by a doctor to use one. One patient shared the nebuliser with a friend.

TABLE I-Normal daily dose of salbutamol taken by 25 patients using nebulisers regularly every day

\begin{tabular}{ccccc}
\hline & \multicolumn{4}{c}{ Daily dose (mg) } \\
\cline { 2 - 5 } $\begin{array}{c}\text { Age } \\
\text { (years) }\end{array}$ & $2 \cdot 5-5$ & $10-15$ & 20 & 30 \\
\hline$<7$ & 3 & 8 & & \\
$7-15$ & 2 & 2 & & 1 \\
$16-54$ & 4 & 1 & 2 & 1 \\
$>54$ & & 1 & & \\
\hline
\end{tabular}

\section{Discussion}

These results show some confusion about the use of nebulisers at home, particularly among patients but also among their doctors. This reinforces our original concern about the safety of home nebulisers.

Some of the patients with nebulisers had not attended a hospital clinic, which raised doubts about whether time had been spent ensuring correct use of the metered dose inhaler or whether an objective evaluation of inhaled steroids had been carried out before prescription. Several studies have shown that lack of response to treatment with a metered dose inhaler has been partially due to the failure of doctors to spend sufficient time instructing patients on correct use. ${ }^{6} 7$ This might also arise with home nebulisers, as a quarter of our patients claimed to have received no instruction on how and when to use their nebuliser.

The wide variation in the dose of bronchodilator used may partially reflect the different types of asthmatic patients using nebulisers. Nevertheless, the doses used make a mockery of the warning printed on one metered dose inhaler that it is dangerous to exceed the recommended dose. Studies have shown that a similar proportion of each dose (roughly 10\%) reaches the lower airways whether it is given by nebuliser or metered dose inhaler ${ }^{8}$ if the metered dose inhaler is taken correctly. A typical nebuliser dose of $5 \mathrm{mg}$ salbutamol delivers 25 times as much drug as the usual dose of $200 \mu \mathrm{g}$ by metered dose inhaler. Thus it is not surprising that patients show a more satisfactory response to the nebuliser. The high prevalence of side effects reported, however, reflects the considerable "overdosage."

The following recommendations give guidelines for the maximum single and daily doses of bronchodilator and refer to treatment by the patient at home.

(1) Nebulisers should be prescribed only after full clinical assessment in a hospital and all other conventional treatments have been shown to fail objectively. 
(2) Nebulisers should be used only in conjunction with a peak flow meter (except in very young children).

(3) Nebulisers should not be used regularly at first but should be reserved for acute exacerbations when peak flow measurements are below a certain predetermined value.

(4) Ideally, a bank of nebulisers should be available for loan so that patients can have a trial period before purchase.

(5) Patients should receive: (a) full instructions on how to use and clean their nebuliser from a suitably trained person such as a respiratory function technician or a physiotherapist, and $(b)$ clear instructions on the use of the nebuliser in an acute attack. Maximum single dose should be $5 \mathrm{mg}$ salbutamol or $10 \mathrm{mg}$ terbutaline, and maximum daily dose $15 \mathrm{mg}$ salbutamol or $30 \mathrm{mg}$ terbutaline. Patients should seek help immediately if the stipulated peak flow response is not achieved or the bronchodilator response is not maintained and start a crash course of oral steroids from a "home depot."

(6) Nebulisers are to be used as an adjunct, not an alternative, to normal treatment for asthma.

(7) Patients using nebulisers should remain under regular surveillance by the district nebuliser service, and arrangements should be made to carry out maintenance on the nebulisers yearly.

The limitations on the maximum dose in the above recommendations will, we hope, remind patients that if their asthma does not respond, alternative treatment such as a crash course of steroids might be more appropriate than increasing the dose of nebulised bronchodilator. Of course, the recommendations do not apply to the dose that can be given by doctors personally, either in the home or in hospital, to treat acute exacerbations. Doses administered to patients with severe chronic airflow obstruction may also be somewhat higher, but many of the other recommendations should still apply.

Most of the children in our survey, who attended the paediatric clinic, were given nebulisers for use with sodium cromoglycate alone, as they were too young to use conventional treatment. In some cases the paediatric clinic was unaware that bronchodilators were also being administered, and the mothers had presumably obtained their supplies of salbutamol from their general practitioners. Many other disquieting facts came to light, such as the unprescribed use of a nebuliser by a child at a play group and by a mother to treat her 9 month old baby.

After these data were presented at a local medical meeting other patients with home nebulisers in the district were brought to our notice, so we cannot claim that this survey is a comprehensive review. Nevertheless, it has confirmed our suspicions that some patients are being prescribed nebulisers with limited or no instruction or supervision, which could lead to disaster.

We thank Dr E M Belton and Dr J Bowyer, consultant paediatricians, for allowing us to study their patients; Mrs E David, paediatric liaison health visitor, for her help in interviewing the parents of children; all those general practitioners who cooperated in this survey; and Mrs Betty Percey for secretarial help.

\section{References}

1 Jackson RT, Beaglehole R, Rea HH, Sutherland DC. Mortality from asthma: a new epidemic in New Zealand. Br Med $\mathcal{F} 1982 ; 285: 771-4$

Khot A, Burn R. Deaths from asthma. Br Med F 1984;289.557. Inman WHW, Adelstein AM. Rise and fall of asthma mortality in England and Wales in relation to use of pressurised aerosols. Lancet 1969;ii:279-85.

Keating G, Mitchell EA, Jackson R, Beaglehole R, Rea $H$. Trends in sales of drugs for asthma in New Zeal

Grant IWB. Asthma in New Zealand. Br Med f 1983;286:374-7.

6 Velling JS, Strohl KP, Smith RL, Altose MD. Physician knowledge in the use of canister nebulisers. Chest $1983 ; 83: 612-4$

Epstein SW, Manning CPR, Ashley MJ, Corey PN. Survey of the clinical use of pressurised aerosol inhalers. Can Med Assoc F 1979;120:813-6.

8 Newman SP, Moren F, Pavia D, Sheahan NF, Clarke SW. Deposition of pressurised aerosols in the human respiratory tract. Thorax 1981;36:52-5.

(Accepted 6 March 1985)

\title{
Serum aluminium concentration and aluminium deposits in bone in patients receiving haemodialysis
}

\author{
SAM A CHARHON, PASCALE M CHAVASSIEUX, PIERRE J MEUNIER, MICHELE ACCOMINOTTI
}

\begin{abstract}
Serum aluminium concentrations and biopsy specimens of bone were examined in 56 patients with end stage chronic renal failure receiving maintenance haemodialysis. Deposits of aluminium in bone specimens were often associated with low bone formation with or without osteomalacia. Serum aluminium concentrations of greater than $3.7 \mu \mathrm{mol} / 1(10 \mu \mathrm{g} / 100 \mathrm{ml})$ indicated a high probability of deposits of aluminium in bone specimens,
\end{abstract}

Institut de la Santé et Recherche Médicale U 234, Faculté A Carrel, 69008 Lyons, France

SAM A CHARHON, MD, research associate

PASCALE M CHAVASSIEUX, MD, research fellow

PIERRE J MEUNIER, MD, professor of medicine

Laboratory of Biochemistry D, Hôpital Edouard Herriot, 69003 Lyons, France

MICHELE ACCOMINOTTI, DPHARM, research assistant

Correspondence to: Dr S A Charhon. although high serum concentrations did not predict the type of renal bone disease.

Biopsy of the bone is the best method of detecting aluminium intoxication of bone. $A$ serum aluminium concentration of $3.7 \mu \mathrm{mol} / 1$ should be the threshold beyond which bone biopsy should be performed to confirm an overload of aluminium and identify histological bone changes induced by aluminium.

\section{Introduction}

Long term consumption of phosphate binders containing aluminium or contamination of dialysis water with aluminium, or both, lead to the accumulation of aluminium in patients with chronic renal failure undergoing haemodialysis. Overload of aluminium has been shown to be responsible for vitamin D resistant osteomalacia, encephalopathy, and anaemia. Serum aluminium concentrations are often increased in these patients, but it is not known whether measurement of these concentrations is useful and sufficiently discriminative for the assessment of aluminium intoxication in patients receiving haemodialysis. 